\title{
Analysis of the Satisfaction Status and Influence Factors of the Standardized Construction of Public Service for National Fitness
}

\author{
Dayong Qiu \\ School of Physical and Health Education, Nanjing Normal University Taizhou Collage, Taizhou, China \\ Email: qiudayongyzh@163.com
}

How to cite this paper: Qiu, D. Y. (2020). Analysis of the Satisfaction Status and Influence Factors of the Standardized Construction of Public Service for National Fitness. Advances in Physical Education, 10, 354-363.

https://doi.org/10.4236/ape.2020.104029

Received: September 27, 2020

Accepted: October 25, 2020

Published: October 28, 2020

Copyright $\odot 2020$ by author(s) and Scientific Research Publishing Inc. This work is licensed under the Creative Commons Attribution International License (CC BY 4.0).

http://creativecommons.org/licenses/by/4.0/

\begin{abstract}
Objective: Under the background of changing government functions, this paper makes an in-depth study on the standardization construction of public service for national fitness, so as to promote its standardized development, so as to meet the needs of the masses for public service of national fitness. Method: This study uses the methods of literature review, questionnaire survey and mathematical statistics. A total of 787 community residents aged 15 - 70 were randomly selected in Taizhou city of Jiangsu Province in November 2019. Result: 1) The overall satisfaction rate of residents to the public service of national construction is $54.4 \%$, and has the characteristics of age, education and occupation. 2) According to the survey on the satisfaction of the contents related to national fitness, the residents' satisfaction with the number, types, convenience and opening hours of the national fitness venues and facilities is $51.21 \%, 48.43 \%, 50.53 \%$ and $54.35 \%$, respectively. However, they are not satisfied with the fees, maintenance and renewal of the facilities, the organization, guidance and consultation of national fitness activities 35\%, $43.17 \%, 36.29 \%, 43.68 \%$ and $43.29 \%$. 3) Through the analysis of the influencing factors of satisfaction with the construction of public service standardization for national fitness, the main reasons for residents' dissatisfaction with the standardization construction of national fitness public service are less participation channels $(\mathrm{OR}=2.169, P=0.021)$, unconnected with residents' needs $(\mathrm{OR}=2.199, P=0.018)$, low participation of residents $(\mathrm{OR}=3.244, P=$ $0.002)$ and lack of standardized talents $(\mathrm{OR}=2.769, P=0.004)$.
\end{abstract}

\section{Keywords}

Fitness for All, Standardization, Satisfaction, Influence Factors 


\section{Introduction}

Since China reform and opening up, economic development has taken a qualitative leap, and the national living standard has changed dramatically. However, with the continuous development of material culture and spiritual culture, people's public demand also shows a diversified and multi-level characteristics, resulting in the current stage of social public services still facing many challenges. The people's awareness of self-development has been strengthened, citizens' awareness of the right to participate in public activities has been continuously raised, people keener and keener to participate in various sports activities, with a view to improving the health index through physical exercise, so as to obtain a higher quality of life. Although the public demand associated with physical exercise is growing, the government provides the public service of national fitness, is still in the stage of low-quality one-way supply. It is difficult to adapt to the current trend of the development and change of public service of national fitness, resulting in the low quality of public service of national fitness, non-equalization and other issues becoming more and more prominent. Therefore, in China, there is an urgent need to promote the national fitness public service towards the direction of system construction. At present, the main problems in the construction of public service standardization for national fitness in China are as follows, there are some problems, such as the lack of understanding of the significance of standardization construction, the lack of sports service system, the weak theoretical basis of sports standardization construction, the imperfect supervision mechanism of standardization construction, and the lack of basic public sports service standardization construction (Wang et al., 2015). Wang \& Guo suggested that the roles and roles of service providers, producers and consumers in equalization should be coordinated, and a unified service standard should be constructed to promote the construction of service-oriented government (2009). In terms of the significance of carrying out the national construction and public service standardization construction, Wang's study showed that strengthening the standardization construction of the national fitness government can promote the equal development of national fitness, improve the quality of public service for national fitness and accelerate the innovation of public service for national fitness (2016). The implementation of the standardization strategy of government public services is conducive to promoting the government to provide public services efficiently ( $\mathrm{Hu} \& \mathrm{Xu}, 2009$ ). The implementation of standardized management of basic public services is conducive to the development of urban and rural areas in the direction of standardization, and is an optimal choice for the overall development of urban and rural areas (Wang \& Guo, 2009).

In 2012, the State Council of the People's Republic of China promulgated the 12th Five-Year Plan for the National Basic Public Service System, which made the construction of the national fitness public service system one of the important tasks. In 2014, China issued the Opinions on accelerating the development of the sports industry to promote sports consumption, for the first time, the na- 
tional fitness promotion to China's national strategic development level, opened a new era of national fitness development. In 2016, China issued the Sports development "13th Five-Year Plan", Determined to accelerate the construction of a standard system for public sports services. And issued the National Fitness Program (2016-2020) in the same year it clearly requires that Governments at all levels should formulate local standards based on local actual conditions and practical experience, and promote the development of equalization and standardization of their services. In this context, to carry out the research on the standardization of public service for national fitness, in line with the requirements of the development, reform and innovation of the national fitness public service, in line with the people's realistic needs for the standardization of the development of national fitness, and speed up the standardization theory and practice of public service for national fitness research, and promote the better and faster development of national fitness.

\section{Research Objects and Methods}

\subsection{Study Subjects}

In this study, the satisfaction and influence factors of the standardized construction of public service for national fitness were studied.

\subsection{Methods}

\subsubsection{Documentation Act}

By consulting the national fitness and national fitness public service, the paper literature of the relevant research lays the theoretical foundation for the development of this research.

\subsubsection{Questionnaire}

In order to understand the satisfaction and influencing factors of public service standardization of national fitness, a questionnaire survey was conducted among 15 - 70 years old community residents in Taizhou city of Jiangsu Province in November 2019. The questionnaire was designed by Liu (2018). According to the needs of this study, Liu's questionnaire was modified, the new questionnaire has a good reliability, $\alpha=0.958$. The questionnaire survey was conducted by combining offline and online methods. 500 questionnaires were distributed offline, 486 were recovered, and the recovery rate was $97.2 \%$. 23 invalid questionnaires were excluded, and 463 valid questionnaires were effective, with an effective rate of $92.6 \% ; 287$ questionnaires were online, with an effective rate of $100 \%$, and 750 offline and online effective questionnaires. Male accounted for $65.51 \%$, female accounted for $34.49 \%$, the age of the respondents was mainly $31-45$ years old (Table 1). The occupational characteristics of the respondents were mainly government and public institution employees (38.68\%), professional skill workers (24.74\%), government leaders, accounting (9.41\%) (Table 2).

\subsubsection{Statistical Method}

The data obtained from the questionnaire are collated and entered into the excel 
Table 1. Gender and age characteristics of the respondents.

\begin{tabular}{cccccc}
\hline Gender & $\mathrm{N}$ & percentage & Age & $\mathrm{N}$ & percentage \\
\hline Male & 491 & $65.51 \%$ & Under 18 years old & 24 & $3.14 \%$ \\
Female & 259 & $34.49 \%$ & 18 - 30 years old & 139 & $18.47 \%$ \\
& & & $31-45$ years old & 358 & $47.74 \%$ \\
& & & 46 - 59 years old & 215 & $28.65 \%$ \\
& & & 60 years old and above & 14 & $2.00 \%$ \\
\hline
\end{tabular}

Table 2. Educational level and occupational characteristics of the respondents.

\begin{tabular}{|c|c|c|c|c|c|}
\hline Education level & $\mathrm{N}$ & percentage & Occupation & $\mathrm{N}$ & percentage \\
\hline No systematic education & 0 & $0.00 \%$ & Government leaders & 70 & $9.41 \%$ \\
\hline Primary school graduation & 0 & $0.00 \%$ & Business executives & 21 & $2.79 \%$ \\
\hline Junior high school graduate & 42 & $5.57 \%$ & $\begin{array}{l}\text { Government and public in- } \\
\text { stitution employees }\end{array}$ & 290 & $38.68 \%$ \\
\hline $\begin{array}{l}\text { Graduation from high school } \\
\text { (including technical } \\
\text { secondary school) }\end{array}$ & 47 & $6.27 \%$ & Professional skill workers & 186 & $24.74 \%$ \\
\hline $\begin{array}{l}\text { Graduated from university } \\
\text { (including junior college) }\end{array}$ & 635 & $84.67 \%$ & Private business owner & 18 & $2.44 \%$ \\
\hline \multirow[t]{7}{*}{ Master degree or above } & 26 & $3.48 \%$ & $\begin{array}{l}\text { individual industrial and } \\
\text { commercial households }\end{array}$ & 26 & $3.48 \%$ \\
\hline & & & Business service employees & 21 & $2.79 \%$ \\
\hline & & & Worker & 18 & $2.44 \%$ \\
\hline & & & Farmer & 3 & $0.35 \%$ \\
\hline & & & soldier & 0 & $0.00 \%$ \\
\hline & & & School students & 47 & $6.27 \%$ \\
\hline & & & Other practitioners & 50 & $6.42 \%$ \\
\hline
\end{tabular}

data sheet, and the percentage and correlation analysis of the data obtained is carried out using SPS 22.0.

\section{Results}

\subsection{National Fitness Public Service Standardized Construction Satisfaction Status}

\subsubsection{Overall Satisfaction of Community Residents with the Standardization of Public Health Services for All}

Satisfaction refers to a psychological feeling after the use of a service or product, which is an important measure of the quality of such a service or product. In 2014, the State Council of the People's Republic of China issued "Several Opinions on Speeding Up the Development of the Sports Industry to Promote Sports Consumption", which raised national fitness as a national strategy, and the whole country responded positively to the call and request of the state, and 
did a lot of work to upgrade the public service for national fitness, and achieved some results. The satisfaction of community residents with the public service of national fitness reflects to a certain extent the level of development of public service of national fitness in the region, and also directly affects the development of mass sports in the region and whether the strategic goal of "Healthy China 2030" can be achieved.

Through the overall satisfaction survey of community fitness public service, the community residents are generally satisfied with the community fitness public service in the region, and from the selection point of view, $54.4 \%$ of the community residents are satisfied with the standardization of community fitness public service construction, but $45.6 \%$ of the community residents still expressed dissatisfaction (Figure 1). The study showed that the construction of public services for all in the area also needs to increase investment in order to meet the needs of community residents fitness exercise.

The age characteristics of community residents' overall satisfaction with the construction of public services for all show that the satisfaction of young people under 18 years of age with the public service of national fitness is low, while the satisfaction of the rest of the population with the public service of national fitness is high (Figure 2).

The educational characteristics of community residents' overall satisfaction with the national fitness public service show that the residents with college degrees have higher overall satisfaction with the standardization construction of

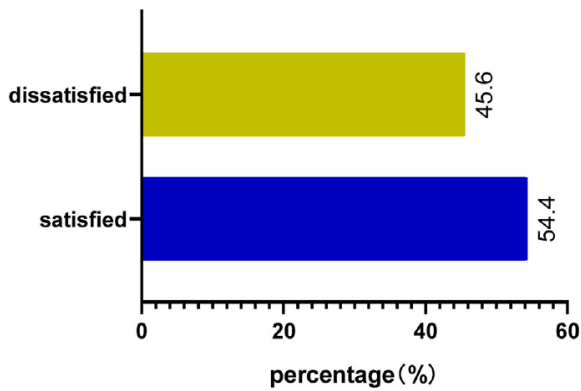

Figure 1. Overall satisfaction with the standardization of public service for national fitness.

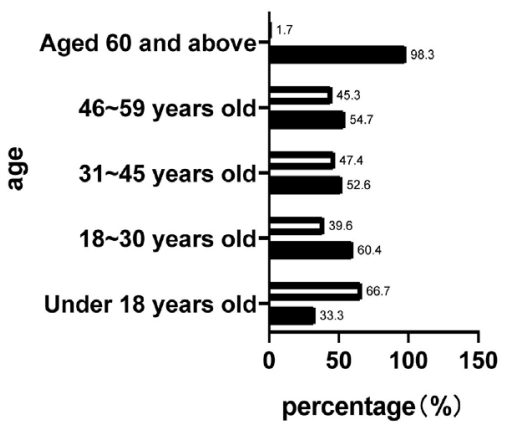

satisfied

ש dissatisfied

Figure 2. Cross-graph of age and satisfaction degree of public service standardization construction of national. 
the national fitness public service and with junior high school education, high school education and graduate education and above, the overall satisfaction with the standardization of public service construction of national fitness is not high, of which graduate students and above are not satisfied with the group of $80 \%$ (Figure 3).

The occupational characteristics of the overall satisfaction of the standardization construction of the national fitness public service show that the overall satisfaction of government department staff, professional and technical personnel, private entrepreneurs and peasant groups to the standardization construction of the national fitness public service is higher, and the satisfaction is more than 50\%; Government leaders, individual industrial and commercial households, workers, military personnel and other professional groups are generally satisfied with the standardization of public services for national fitness, while enterprise executives and student groups are generally satisfied with the national fitness public service (Figure 4).

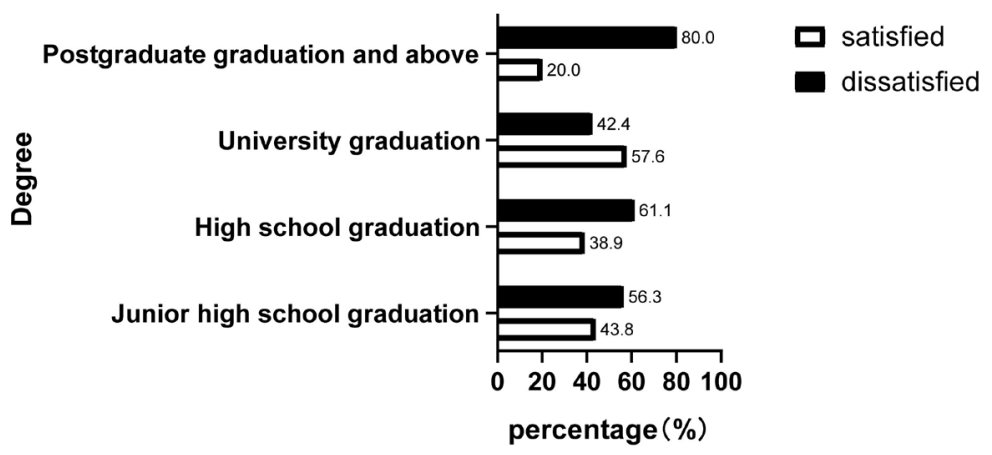

Figure 3. Cross-graph of degree and satisfaction of public service standardization construction of national fitness.

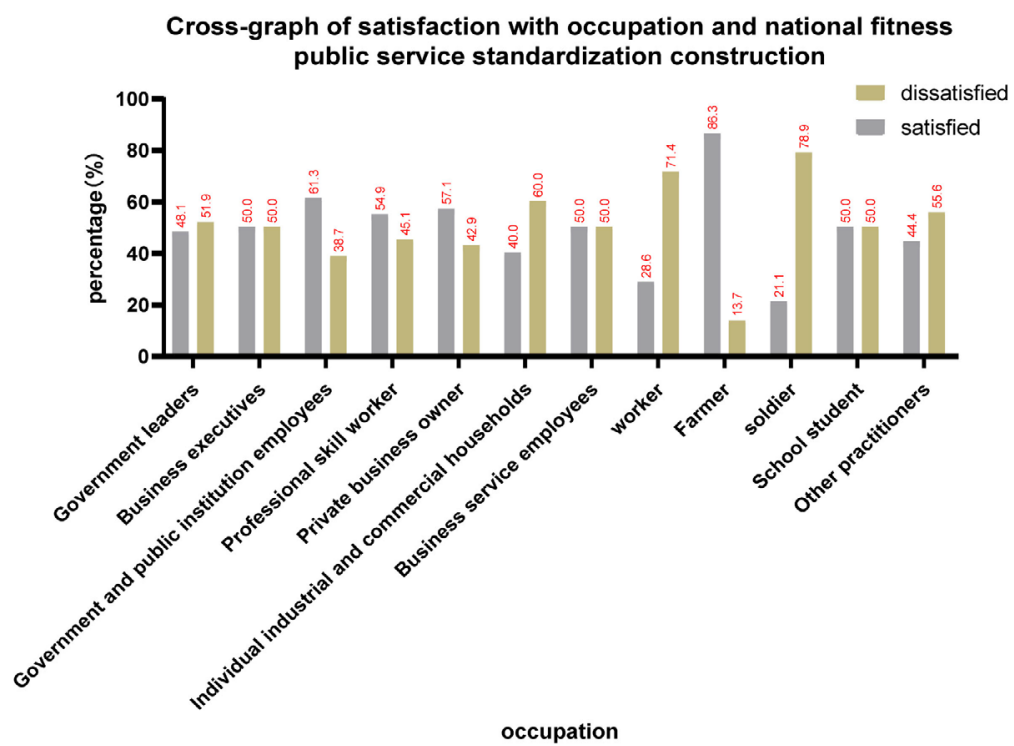

Figure 4. Cross-graph of satisfaction with occupation and national fitness public service standardization construction. 


\subsubsection{Satisfaction with the Content Related to the Standardization of Public Service for National Fitness}

Select the number, type, convenience, charging situation, opening hours, facilities update and maintenance, the organization, guidance of national fitness activities, as well as the national fitness consultation 9 aspects of content, as the national fitness public service standardization of the main content of the construction of satisfaction survey.

The results of the survey showed that the community residents were satisfied with the number, type, convenience and opening hours of the national fitness facilities, with $51.21 \%, 48.43 \%, 50.53 \%$ and $54.35 \%$ respectively. Fitness venue facilities charge, maintain and update, the organization, guidance and national fitness consultation of national fitness activities are more dissatisfied, choose not satisfied with the following are $51.35 \%, 43.17 \%, 36.29 \%, 43.68 \%$ and $43.29 \%$ (Figure 5).

\subsection{Analysis of the Factors Affecting the Standardization of National Fitness Public Service Construction}

The dependent variable is whether the community residents are satisfied with the standardized construction of public service for national fitness (satisfaction = 0 , dissatisfaction $=1$ ), The standardization construction is not transparent, residents do not understand, the residents do not know the standard, the awareness of participation is weak, the residents lack the corresponding knowledge of standardization construction, the residents' opinions are not accepted, there are few alternative ways to participate, the content of standardization construction is not complete, it is not linked with the needs of residents, the process of standardization construction is unscientific, and lacks systematicness and foresight. The

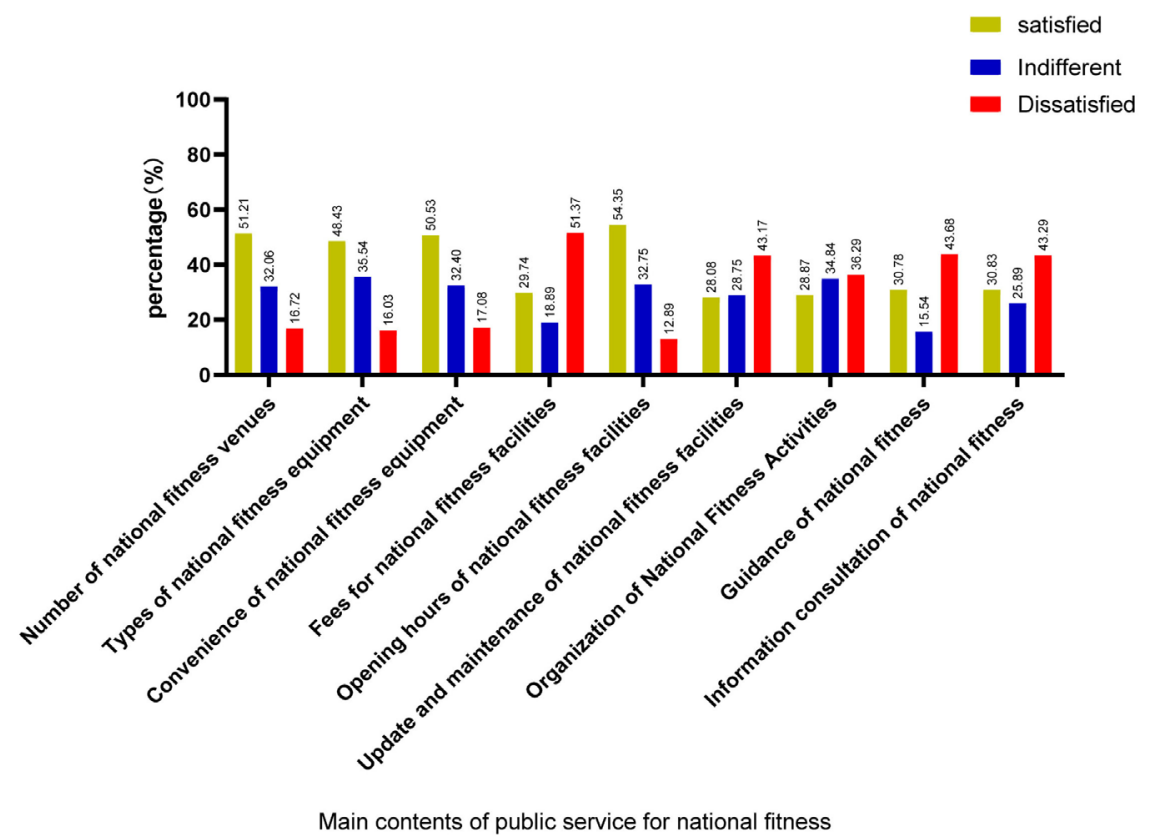

Figure 5. Content satisfaction of subjects related to public service of national fitness. 
covariates are unreasonable, lack of supervision in the process of standardization construction, low participation of residents, lack of special organizational departments, lack of fund guarantee, imperfect standardization construction system and lack of standardized talents, Binary logistic regression showed that the main reasons for residents' dissatisfaction with the standardization construction of national fitness public service are the lack of alternative participation channels $(\mathrm{OR}=2.169, P=0.021)$, the lack of connection with residents' needs (OR $=$ 2.199, $P=0.018)$, the low participation of residents $(\mathrm{OR}=3.244, P=0.002)$ and the lack of standardized talents $(\mathrm{OR}=2.769, P=0.004)$ (Figure 6).

\section{Discussion}

The public service of national fitness is the basic public sports service provided by the government to meet the public's participation in sports activities. Standardization is the activity of making normative documents for things and concepts commonly used and reused in the fields of science, technology and experience (Wang et al., 2015). In the last century, the concept of public service standardization has been widely spread and widely used in the field of public service in developed countries in Europe and America. Public service standardization is to achieve social equity and improve the efficiency of public services, to ensure the transparency and standardization of government services.

At present, China's national fitness public service is in the implementation of the "national strategy for national fitness" and the comprehensive deepening reform and development of public service standardization (Wang, 2016). Research on Residents' satisfaction with the construction of public service standardization of national fitness can accelerate the development of public service for national fitness. According to the general satisfaction survey of public service standardization construction of national fitness, most community residents are satisfied with the standardization construction (54.4\%), but there are still $45.6 \%$ community residents that are not satisfied with the standardization construction. Shanghai citizens have low satisfaction with the public service of national fitness (Liu, 2018), this is not consistent with my research results, the reason may be Shanghai is an international metropolis, the public's understanding and requirements for the public service of national fitness are higher than those of

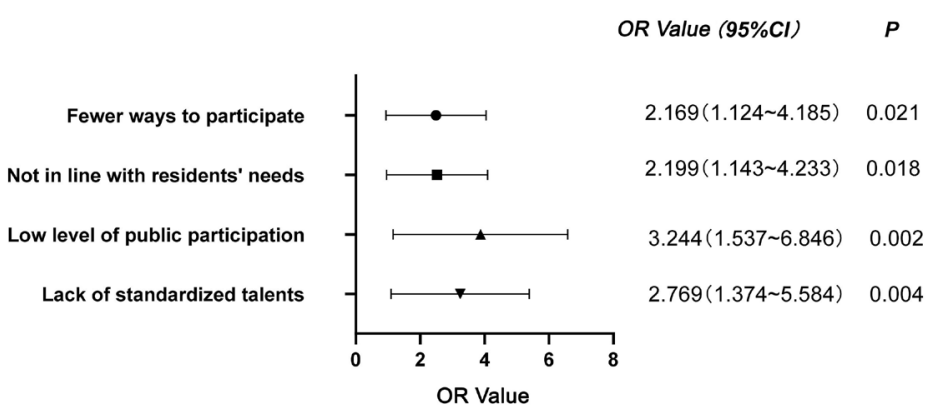

Figure 6. Logistic regression analysis on influencing factors of satisfaction degree of public service standardization of national fitness. 
ordinary cities. However, the age characteristics of the total satisfaction of the national fitness public service standardization construction show that the dissatisfaction of the young students under the age of 18 is high, which may be related to the diversified fitness needs of the young students. The young students pay more attention to the emerging sports activities, while the venues and facilities provided by the public service of national fitness are still in the traditional sports, which cannot meet the needs of the young students. The educational characteristics of the overall satisfaction degree of the public service standardization construction of national fitness show that the highest degree of dissatisfaction is among the graduate students and above, which may be related to the higher requirements on the standard of fitness venues and facilities with the improvement of cognitive level. In terms of satisfaction with the contents related to the standardization of public service for national fitness, the residents of Suzhou are more satisfied with the national fitness facilities, the number of public sports venues and opening hours (Cui, 2019), My research has come to the same conclusion, the reason may be Jiangsu province belongs to China's economically developed province, which ensures that more funds are invested in the public service of national fitness.

The main reasons that perplex the construction of public service standardization of national fitness in Shanghai are that the citizen participation mechanism is not perfect, the theoretical basis of standardization is weak, the idea is not paid attention to, the propaganda is insufficient, the lack of standardized talents, and the theme content is defective. Through the regression analysis of the influencing factors of the satisfaction degree of the public service standardization construction of national fitness, it is found that the community residents think that in the process of the construction of the public service for national fitness, the residents can choose fewer ways to participate, the public service provided by the government is not connected with the needs of the residents, the public participation is low in the process of the construction of the national fitness public service standardization, and the lack of standardized talents Four aspects are the main reasons for residents' dissatisfaction with the construction of public service standardization of national fitness. It shows that in the process of providing public services, the government still has the "extensive" management mode, which only pays attention to the common supply, regardless of the actual needs of the masses. The lack of scientific, systematic and guidance of sports standardization construction [4], and the lack of attention to personnel training, resulting in the lack of depth of public service standardization construction of national fitness.

\section{Conclusion}

This study shows that the community residents are generally satisfied with the construction of comprehensive fitness public service standardization, and most age groups are satisfied with the construction of public service standardization of national fitness. In the process of national fitness public service standardiza- 
tion construction, the residents can choose fewer participation channels, the public service provided by the government is not connected with the residents' demand, and the low participation of citizens and the lack of standardized talents are the main causes of residents' dissatisfaction with the public service of national fitness.

The limitation of this study is that the survey scope is not wide enough, the number of respondents is relatively insufficient, and the rural residents' satisfaction with the construction of national fitness public service standardization is not involved. The research needs to be improved in the future.

\section{Funding}

"Analysis on the current situation and influencing factors of standardization construction of public service for national fitness in Taizhou" funded by Taizhou Science and Technology Bureau of Jiangsu Province (RKX201911).

\section{Conflicts of Interest}

The author declares no conflicts of interest regarding the publication of this paper.

\section{References}

Cui, J. J. (2019). Research on High Quality Development of Public Sports Service Based on Satisfaction Survey. Journal of Wushu Research, 4, 129-131.

Hu, S. G., \& Xu, Y. S. (2009). A Study on the Value of Public Service Standardization. Journal of Gansu University of Administration, 5, 47-52+22.

Liu, C. (2018). Standardization Construction of National Fitness Public Service of Shanghai. Master's Thesis, Shanghai: Shanghai Institute of Physical Education.

Wang, F. (2016). A Study of National Fitness Public Service Standardization. Journal of Physical Education, No. 3, 46-52.

Wang, L., Meng, Y.-Z. et al. (2015). Constitution and Standardization of Public Service System of Fitness for All. Journal of Beijing Sport University, No. 38, 1-7.

Wang, Z. Z., \& Guo, Z. L. (2009). On the Influential Factors of Public Service Equality and the Construction of Standardization System. Academic Research Journal, 6, 59-63. 